\title{
Углеродные адсорбенты на базе растительных отходов Мьянмы как средства очистки производственных выбросов и сбросов
}

\author{
Наинг Линн Сое, Зин Мое, Мин Тху, Мьят Мин Тху, Со Вин Мьинт, \\ Нистратов А.В., Клушин В.Н.
}

Российский химико-технологический университет имени Д.И. Менделеева, Москва

Поступила в редакцию 14.07.2019 г.

DOI: $10.17308 /$ sorpchrom.2019.19/1172

Представлены основы технологии переработки фрагментов крупнотоннажных растительных отходов предприятий Мьянмы в виде скорлупы орехов кокоса и косточек сливы, древесины бирманского железного дерева, оболочек семян манго, рисовой шелухи и гуза-паи - полевых остатков возделывания хлопчатника на активные угли методом их пиролиза и активации карбонизатов водяным паром. Охарактеризованы технические показатели полученных в оптимальных условиях целевых продуктов и сопоставительные результаты эффективности их использования при очистке сточных вод и газовых выбросов.

Ключевые слова: растительные отходы Мьянмы: фрагменты скорлупы кокосовых орехов и косточек сливы, древесины бирманского железного дерева, оболочек семян манго, рисовой шелухи, гуза-паи - полевых отходов выращивания хлопчатника; пиролиз, активация водяным паром, карбонизаты, активные угли, условия получения, пористая структура, поглотительная способность, эффективность очистки сточных вод и улавливания паров летучих органических растворителей: сопоставительная оценка.

\section{Carbon adsorbents based on myanmar plant wastes as cleaning agent of industrial emissions and discharges}

\author{
Naing Lin Soe, Zin Moe, Min Thu, Myat Min Thu, Saw Win Myint, \\ Nistratov A.V., Klushin V.N.
}

\section{D.I. Mendeleev University of Chemical Technology of Russia, Moscow}

In numerous productions of the Republic of the Union of Myanmar burdensome large-amount of plant waste is formed. Sources of scientific and technical information indicate the principal possibility of obtaining of activated carbon on their base, suitable for solving the problems of cleaning and neutralization of a wide range of discharges and emissions of various enterprises and industries. The purpose of the study is to evaluate in solving these problems the feasibility and effectiveness of using carbon adsorbents, obtained by pyrolysis of representative samples of these wastes of national production (in the form of fragments of coconut shells and plum seeds, Burmese iron-wood, mango seed shells, Guza-Pai - field residues of cultivation of cotton and rice husks) and the steam activation of its carbonized material, as the most simple and affordable technology for implementation in condition of Myanmar. The optimal conditions for the implementation of these operations and technical parameters (yield, porous structure, absorption capacity, specific consumption of steam, bulk density, abrasion resistance) of the obtained adsorbents are characterized. Characterizations of the scientific novelty of the studying results of comparative evaluation of the effectiveness of their use in solving the problems of multicomponent wastewater treatment (for example, wastewater release № 1 JSC «Moskoks») and recuperation of vapors of volatile organic solvents (for example, n-butanol) from their mix- 
tures with air are presented. It is stated that for a number of parameter (yield, porosity, absorption capacity and other characteristics), not all of the obtained activated carbons reach the level of the best adsorbents on the base of the corresponding similar waste, but can be competitive products in the organization of their production in Myanmar, practically without enterprises of this profile, but experiencing significant needs in their products, poorly satisfied due to the significant market price of activated carbon.

Keywords: Myanmar plant waste, fragments of coconut shell and plum seeds, burmese iron-wood, mango seed shells, rice husk, Guza-Pai - the field residues of cotton cultivation; the pyrolysis, steam activation, carbonized material, activated carbon, obtained condition, porous structure, absorption capacity, the efficiency of wastewater treatment and recuperation of vapors of volatile organic solvents, comparative evaluation.

\section{Введение}

Функционирование многих производств республики Союз Мьянма сопровождает образование крупнотоннажных растительных отходов, представляющих собой перспективное сырье для получения углеродных адсорбентов, в частности, активных углей. Это обстоятельство имеет важное значение для экономики государства, политика которого в области обращения с древесными и смежными им отходами преследует цель их рационального использования [1-3], но практически не располагающего собственными производствами таких адсорбентов. В стране с целью экспорта с использованием японской техники производит активный уголь, главным образом из бамбука, в количестве 20-30 т/год лишь компания «Rectangle Co., Ltd» на фабрике в г. Зейявадди, район Таунгнгу [4]. Наряду с этим ее предприятия испытывают острую потребность в углеродных адсорбентах для решения ансамбля экологических проблем, слабо удовлетворяемую из-за высокой стоимости этой продукции на мировом рынке. В этой связи организация в стране на базе указанных отходов собственного производства данного типа продукции актуальна и требует, прежде всего, обоснования его технологических основ и оценки качества получаемых адсорбентов. Ниже представлена информация, ориентированная на перспективу возможного решения задачи эффективного вовлечения ряда представителей названных отходов в материальное производство с получением углеродных адсорбентов.

\section{Эксперимент}

В качестве наиболее перспективных среди названных крупнотоннажных отходов национальных производств Мьянмы в работе исследованы воздушно-сухие фрагменты скорлупы орехов кокоса (СКО) и косточек сливы (СКС), рисовой шелухи (РШ), древесины бирманского железного дерева (ДЖД), оболочек семян манго (ОСМ) и гуза-паи (ГП) - полевых остатков выращивания хлопчатника, многие из которых, согласно имеющимся публикациям [5-14], пригодны для утилизации с указанной целью. Изначально для их переработки использована наиболее доступная к реализации в условиях страны вследствие своей относительной простоты технология пиролиза сырья с последующей активацией его карбонизированных продуктов водяным паром.

Оптимальные условия проведения этих операций (интенсивность нагревания $v$, предельная температура $t$, длительность изотермической выдержки при ней $\tau$ и удельный расход водяного пара на единицу получаемого активного угля Р) наряду с показателями выхода по отношению к сырью В, плотности $\mathrm{d}$ и прочности при истирании П карбонизатов (числитель) и активных углей (знаменатель) характеризуют данные табл. 1.

Зольность охарактеризованных сырьевых материалов и продуктов их названной переработки возрастает в ряду «сырье-карбонизат-активный уголь», составляя в 
процентах 1.11-2.03-2.93 для СКО, 0.6-0.90-1.7 для СКС, 22.57-48.54-50.74 для РШ, 1.0-1.6-3.3 для ДЖД, 1.4-3.0-5.7 для ОСМ и 1.7-3.4-6.2 для ГП.

Таблица 1. Условия обработки сырья и показатели целевых продуктов

\begin{tabular}{|c|c|c|c|c|c|c|c|}
\hline \multirow{2}{*}{ Сырье } & \multicolumn{3}{|c|}{ Оптимальные условия } & \multicolumn{3}{c|}{ Свойства продуктов } \\
\cline { 2 - 8 } & $\begin{array}{c}v, \\
{ }^{\circ} \text { С/мин }\end{array}$ & $\mathrm{t},{ }^{\circ} \mathrm{C}$ & $\tau$, мин & $\begin{array}{c}\text { Р, } \\
\text { кг/кг }\end{array}$ & $\mathrm{B}, \%$ & $\mathrm{~d}$, кг/дм ${ }^{3}$ & П, \% \\
\hline СКО & $15 / 15$ & $700 / 850$ & $180 / 60$ & 3 & $25.3 / 15.3$ & $0.54 / 0.41$ & $97.7 / 98.0$ \\
\hline СКС & $15 / 15$ & $600 / 850$ & $10 / 30$ & 15 & $31.8 / 23.9$ & $0.30 / 0.24$ & $98.0 / 90.0$ \\
\hline РШ & $15 / 15$ & $650 / 750$ & $30 / 30$ & 7 & $42.3 / 38.5$ & $0.11 / 0.08$ & $44.7 / 28.0$ \\
\hline ДЖД & $15 / 15$ & $550 / 850$ & $60 / 60$ & 5 & $29.3 / 11.7$ & $0.21 / 0.17$ & $98.0 / 60.0$ \\
\hline ОСМ & $10 / 10$ & $600 / 800$ & $30 / 90$ & 5 & $24.8 / 10.1$ & $0.12 / 0.14$ & $97.0 / 66.8$ \\
\hline ГП & $10 / 5$ & $750 / 800$ & $60 / 45$ & 15 & $26.1 / 19.6$ & $0.18 / 0.13$ & $86.0 / 53.0$ \\
\hline
\end{tabular}

Результаты тестирования пористой структуры и адсорбционной способности целевых продуктов названной переработки отходов, выполненного с использованием традиционных оценок величин суммарного объема пор по воде $\left(\mathrm{V}_{\Sigma}\right)$, объемов сорбирующих пор $\left(\mathrm{V}_{\mathrm{s}}\right)$ по парам $\mathrm{H}_{2} \mathrm{O}, \mathrm{CCl}_{4}$ и $\mathrm{C}_{6} \mathrm{H}_{6}$, поглощения йода $\left(\mathrm{J}_{2}\right)$ и красителя метиленового голубого (МГ), представлены в табл. 2.

Таблица 2. Показатели пористости и поглотительных свойств карбонизатов (числитель) и активных углей (знаменатель)

\begin{tabular}{|c|c|c|c|c|c|c|}
\hline \multirow{2}{*}{ Объект } & \multicolumn{7}{|c|}{ Показатели } \\
\cline { 2 - 7 } & $\begin{array}{c}\mathrm{V}_{5}, \\
\mathrm{~cm}^{3} / \Gamma\end{array}$ & $\begin{array}{c}\mathrm{V}_{\text {sн20, }} \\
\mathrm{cm}^{3} / \Gamma\end{array}$ & $\begin{array}{c}\mathrm{V}_{\text {sСС14, }} \\
\mathrm{cm}^{3} / \Gamma\end{array}$ & $\begin{array}{c}\mathrm{V}_{\text {sС6н6, }} \\
\mathrm{cm}^{3} / \Gamma\end{array}$ & $\begin{array}{c}\mathrm{J}_{2}, \\
\%\end{array}$ & $\begin{array}{c}\text { МГ, } \\
\text { мГ/Г }\end{array}$ \\
\hline СКО & $0.16 / 0.38$ & $0.15 / 0.37$ & $0.03 / 0.14$ & $0.16 / 0.32$ & $40.30 / 62.05$ & $5.3 / 280.7$ \\
\hline СКС & $0.68 / 0.92$ & $0.09 / 0.19$ & $0.06 / 0.34$ & $0.18 / 0.37$ & $77.19 / 86.73$ & $3.5 / 153.0$ \\
\hline РШ & $1.37 / 1.27$ & $0.11 / 0.13$ & $0.09 / 0.08$ & $0.11 / 0.16$ & $70.30 / 78.80$ & $305.0 / 535.0$ \\
\hline ДЖД & $0.70 / 1.57$ & $0.11 / 0.13$ & $0.03 / 0.67$ & $0.15 / 0.78$ & $41.20 / 98.10$ & $3.5 / 400.0$ \\
\hline ОСМ & $0.87 / 1.25$ & $0.13 / 0.15$ & $0.05 / 0.31$ & $0.17 / 0.31$ & $29.4 / 104.8$ & $6.9 / 210.4$ \\
\hline ГП & $1.32 / 1.79$ & $0.13 / 0.23$ & $0.03 / 0.26$ & $0.12 / 0.26$ & $71.1 / 34.29$ & $6.6 / 204.0$ \\
\hline
\end{tabular}

Эффективность прикладного использования полученных адсорбентов, за исключением активного угля на основе гуза-паи, оценена на примере обработки ими образцов многокомпонентных стоков АО «Москокс», охарактеризованных в работе [18], и модельных паро-воздушных смесей н-бутанола, как представителя широкого круга летучих органических растворителей.

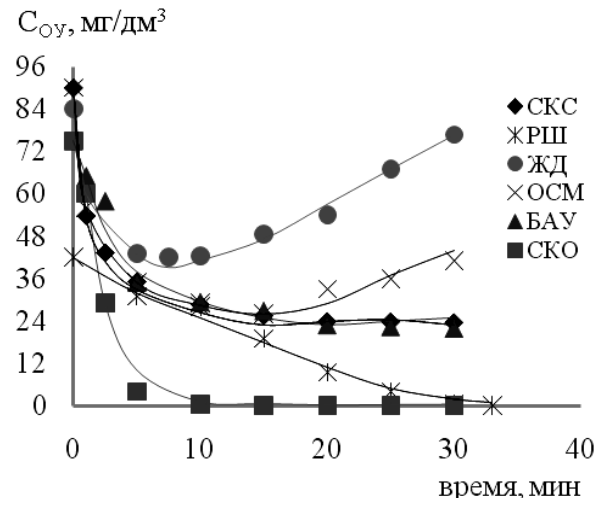

Рис. 1. Кинетические кривые очистки стоков АО «Москокс» разными активными углями на растительной основе (зерна фракции 0.5-1.0 мм, доза 0.3 г/дм $\left.{ }^{3}, 20^{\circ} \mathrm{C}, \mathrm{Re}_{\mathrm{м}}=2500-2600\right)$

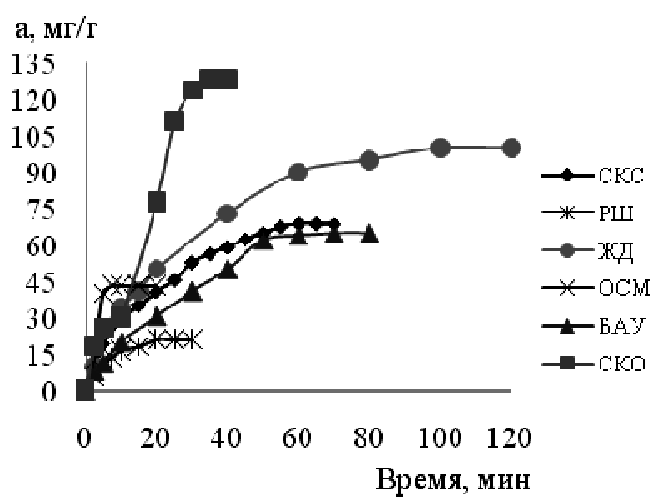

Рис. 2. Кинетика адсорбции при $20^{\circ} \mathrm{C}$ паров бутанола из воздуха при $\mathrm{p} / \mathrm{p}_{\mathrm{s}}=0.4$ зернами 2-4 мм активных углей (удельный расход потока 2.5 дм $\left.^{3} /\left(\mathrm{cm}^{2} \cdot \mathrm{Mин}\right)\right)$ 
На рис. 1 охарактеризована кинетика очистки разными активными углями на растительной основе в порошковом виде образцов стоков АО «Москокс», отобранных в различные периоды года и имеющих неодинаковый состав, характеризуемый для присутствующей органики показателем органического углерода.

Рисунок 2 характеризует результаты изучения кинетики адсорбции различными углями на растительной основе паров бутанола из их смеси с воздухом в идентичных условиях экспериментов. Адсорбционное равновесие в изученных системах «уголь-пары бутанола» характеризуют данные рис. 3.

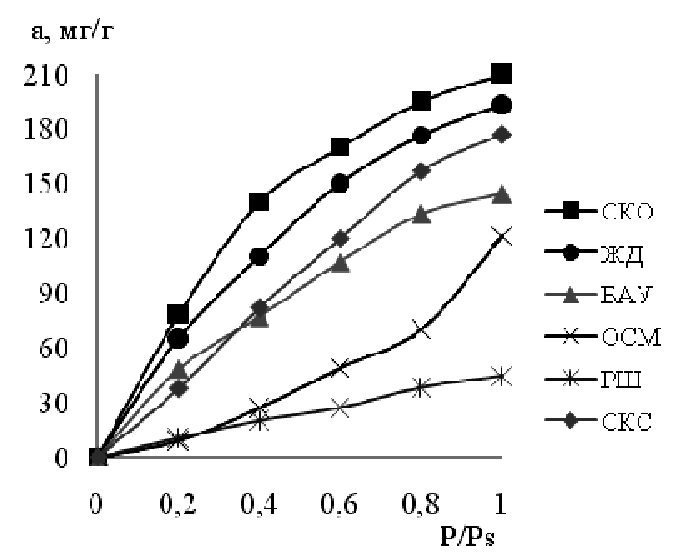

Рис. 3. Оценочные данные по равновесию адсорбции при $20^{\circ} \mathrm{C}$ паров бутанола исследованными активными углями

\section{Обсуждение результатов}

Данные табл. 1 и 2 свидетельствуют, что наиболее микропористым среди охарактеризованных адсорбентов является активный уголь, полученный на базе СКО. Он же наряду с углем на базе СКС наиболее прочен. В целом же ряд его показателей существенно уступает аналогичным показателям активных углей на кокосовой основе, описанных в обзоре работы [4].

В статье [15] охарактеризованы активные угли, полученные из скорлупы косточек абрикосов, слив и персиков. Их насыпная плотность составляет 0.4-0.6 г/ $\mathrm{cm}^{3}$, величина $\mathrm{V}_{\mathrm{SC6H}},-0.6-0.8 \mathrm{~cm}^{3} / \Gamma$, объемы микро- и мезопор - 0.35-0.45 и 0.5-0.8 $\mathrm{cm}^{3} / \Gamma$ соответственно. В сравнении с углем на основе СКС их отличает большая степень обгара (60-75\%) и, напротив, меньшая прочность при истирании (65-80 \%). Авторами подчеркнуто, что названным углям свойственны весьма высокая химическая устойчивость, возможность цикличной эксплуатации и повышенная механическая прочность при высокой (0.8-1.1 см $\left.\mathrm{cm}^{3} / \Gamma\right)$ пористости. Результаты получения активных углей различными приемами парогазовой активации карбонизатов косточковых отходов переработки плодов ряда фруктовых культур (абрикосов, вишни, черешни, сливы, винограда, персика) наряду со скорлупой орехов изложены в работе [16]. Их качество отражено величинами поглощения МГ и удельной поверхности $\mathrm{S}_{\text {уд }}$ В соответствии с последней лучшим является уголь на базе абрикосовых косточек с величиной $\mathrm{S}_{\text {уд }}$ около $600 \mathrm{~m}^{2} /$ и и выходом $10.1 \%$, существенно меньшим, чем для углей на основе СКО и СКС.

Целевой продукт названной переработки РШ по существу является высокоминерализованным кремнеуглеродным материалом, в качестве адсорбента значительно уступающим производным термической переработки этих отходов, охарактеризованным, в частности, в работах $[10,11]$. 
Сопоставление свойств активного угля, полученного в охарактеризованных выше условиях из отходов ДЖД, с таковыми других активных углей на древесной основе по данным [17] свидетельствует о его существенном превосходстве в объеме мезопор.

Активный уголь паровой активации на базе отходов в виде ОСМ имеет прочность при истирании, превосходящую значения этого показателя для углей, полученных из близких по природе отходов ДЖД и гуза-паи, но по поглотительным свойствам существенно уступает активным углям, полученным из этого сырья согласно [5-7].

Сопоставление приведенных выше данных относительно продукта переработки отходов возделывания хлопчатника с величинами аналогичных показателей карбонизата и активного угля, полученных в работе [14] из образца гуза-паи, отобранного в Джизакской области Узбекистана, позволяет отметить, что выход целевых продуктов обеих операций переработки гуза-паи из Мьянмы, как и значения их гравиметрической плотности и поглощения йода несколько ниже, однако показатели адсорбции $\mathrm{C}_{6} \mathrm{H}_{6}$ и красителя метиленового голубого выше.

Исходя из данных рис. 1, можно констатировать, что максимально эффективную $(99.8 \%)$ и быструю (практически на 7-й минуте контакта фаз) очистку стока с начальной величиной $\mathrm{C}_{\mathrm{O}}=75.0$ мг/дм ${ }^{3}$ обеспечивает уголь, полученный из скорлупы кокосовых орехов. Существенно менее значимы показатели эффективности использования угля БАУ $(70.7 \%)$ и угля на основе СКС (53.7\%) при обработке стоков с $\mathrm{C}_{\mathrm{Oy}}=75.0$ и 53.7 мг/дм ${ }^{3}$ соответственно, обеспечивающих завершение очистки к 20-й минуте контакта фаз. Использование углей на базе отходов ОСМ и ДЖД характеризует эффективность очистки в 71.1 и $50.0 \%$ при близких величинах $\mathrm{C}_{\mathrm{Oy}}$, составляющих 84.0 и 90.0 мг/дм ${ }^{3}$ на 8-й и 10-й минутах контакта фаз соответственно. Последующий их контакт с образцами сточной воды вызывает рост показателя $\mathrm{C}_{\mathrm{Oy}}$, обусловленный явлениями вытеснительной сорбции [18]. Углеродминеральный адсорбент на базе РШ демонстрирует высокую (практически 100\%-ную) эффективность очистки при обработке стока с $\mathrm{C}_{\mathrm{O}}=42$ мг/дм ${ }^{3}$ и наиболее длительную (наименее интенсивную) кинетику процесса.

Как свидетельствуют данные рис. 2, максимальной адсорбционной способностью (128 мг/г) и практически приемлемой длительностью ее достижения ( 35 мин) обладает уголь на основе СКО. Меньшей емкостью (100.0 мг/г) и большей длительностью насыщения (100 мин) характеризуется уголь на базе ДЖД. Еще более низкую величину предельного поглощения (68.8 мг/г), реализуемую к 60-й минуте контакта фаз, демонстрирует уголь, полученный из СКС. Последнему уступает уголь марки БАУ, так как его максимальная адсорбция (65 мг/г) достигается на такой же длительности процесса. Активный уголь, полученный из ОСМ, имеет еще более низкую величину поглощения (43 мг/г), обеспечиваемую наиболее быстро (практически на 8-й минуте реализации процесса). Кремнеуглеродный адсорбент на базе РШ характеризует наименьшая величина поглощения бутанола (21 мг/г), достигаемая в течение 20 мин. Характеризуемое данными рис. 3 адсорбционное равновесие в изученных системах «уголь-пары бутанола» свидетельствует о весьма низкой целесообразности практического использования адсорбентов, полученных из ОСМ и РШ, в задачах рекуперации паров летучих органических растворителей.

\section{Заключение}

Представленная информация позволяет заключить, что активные угли, полученные из использованных в работе растительных отходов Мьянмы путем пиролиза 
и высокотемпературной обработки его целевых продуктов водяным паром, имеют технические показатели, ряд которых не соответствует уровню таковых для лучших адсорбентов на основе однотипных отходов, охарактеризованных в доступных литературных источниках. Тем не менее, ряд их может являться конкурентоспособной продукцией при организации их производства в условиях Мьянмы. Совершенствование качества названных адсорбентов требует дополнительных исследований, связанных с вопросами подготовки сырья и иными приемами его термической переработки.

\section{Список литературы}

1. Forest resources of Myanmar: [Электронный pecypc]. - Режим доступа: http://www.timbertradeportal.com/countries/my anmar/ (дата обращения: 01.08.2018).

2. Department of Agriculture (DOA). Ministry of Agriculture and Irrigation, Department of Agriculture, Myanmar Horticultural Crops Production Report (2010-2011): [Электронный ресурс]. - Режим доступа: http://www.fao.org/fileadmin/user_upload/faow eb/docs/MM3/Statements/Myanmar.pdf (дата обращения: 27.10.2018).

3. Экономика Мьянмы: [Электронный реcypc]. - Режим доступа: https://Myanmar. mid.ru/ekonomika-m-anmy (дата обращения: 08.10.2017).

4. Со Вин Мьинт. Переработка скорлупы орехов кокоса республики Мьянма в активные угли: дисс... канд. техн. наук. М., 2017. $-145 \mathrm{c}$.

5. Akpen G.D., Nwaogazie I.L., Leton T.G. // Indian Journal of Science and Technology. 2011. Vol. 4. No 8. pp. 890-894.

6. Rai M.K., Shahi G., Meena V., Meena R., Chakraborty S. et al. Preparation and characterization of activated carbon from mango seed kernel for heavy metal removal from aqueous solution: [Электронный pecypc]. - Режим доступа: https://www.researchgate.net/publication /310369535 (дата обращения: 20.09.2017).

7. Akpen G.D., Nwaogazie I.L., Leton T.G. // Journal of Applied Science and Technology. 2014. Vol. 19. No 1, 2. pp. 43-48.

8. Кудайбергенов К.К. Дисс... д.ф. (PhD). Алматы. 2012. $101 \mathrm{c.}$

9. Получение сорбентов карбонизацией рисовой шелухи для очистки воды от нефте-

\section{References}

1. Forest resources of Myanmar: [Elektronnyy resurs], продуктов: [Электронный ресурс]. - Режим доступа: https://docviewet.yandex.ru/?urI= http\%3A\%2F\% 2Fpratsi.opu/ua\%2Fapp\% 2 Fwebroot $^{\mathrm{c}}$. (дата обращения: 3.08.2016).

10. Елецкий П.М. Дисс. на соискание ученой степени к.Х.н. Новосибирск. 2009. 115 с.

11. Холомейдик А.Н. Дисс. на соискание ученой степени к.Х.н. Владивосток. 2016. 136 c.

12. Епифанцева Н.С., Симкин Ю.Я. // Современные проблемы науки и образования. PAEH. 2008. № 4. C. 25-26.

13. Khalil L.B. // Adsorpt. Sci. and Technol. 1996. Vol. 13. No 5. pp. 317-325.

14.Сербина Т.В. Дисс... к.т.н. М.: МХТИ. 1993. $223 \mathrm{c}$.

15. Галушко Л.Я., Хазипов В.А., Пащенко Л.В., Саранчук В.И. // Химия твердого топлива. 1998. № 3. С. 33-37.

16.Касьянов Г.И., Нематуллаев И., Палагина И.А. и др. Производство активного угля из скорлупы косточек плодовых культур и его регенерация: [Электронный ресурс]. режим доступа: https://cyberleninka.ru/article/n/proisvodstvoactivnogo-uglya-iz-... (дата обращения: 17.06.2018).

17.Мухин В.М., Клушин В.Н. Производство и применение углеродных адсорбентов. Учебное пособие. М.: РХТУ им. Д.И. Менделеева. 2012. 308 с.

18.Зубахин Н.П., Клушин В.Н., Старостин К.Г., Нистратов А.В. // Кокс и химия. 2015. № 2. C. 39-43.

http://www.timbertradeportal.com/countries/my anmar/ (data obrashcheniya: 01.08.2018). 
2. Department of Agriculture (DOA). Ministry of Agriculture and Irrigation, Department of Agriculture, Myanmar Horticultural Crops Production Report (2010-2011): [Elektronnyy resurs].

http://www.fao.org/fileadmin/user_upload/faow eb/docs/MM3/Statements/Myanmar.pdf (data obrashcheniya: 27.10.2018).

3. Ekonomika M'yanmy: [Elektronnyy resurs]. https://Myanmar.mid.ru/ekonomika-manmy (data obrashcheniya: 08.10.2017).

4. So Vin M'int. Pererabotka skorlupy orekhov kokosa respubliki M'yanma v aktivnye ugli: diss... kand. tekhn. Nauk, M., 2017, 145 p.

5. Akpen G.D., Nwaogazie I.L., Leton T.G., Indian Journal of Science and Technology, 2011, Vol. 4, No 8, pp. 890-894.

6. Rai M.K., Shahi G., Meena V., Meena R., Chakraborty S. et al., Preparation and characterization of activated carbon from mango seed kernel for heavy metal removal from aqueous solution: [Elektronnyy resurs]. https://www.researchgate.net/publication/31036 9535 (data obrashcheniya: 20.09.2017).

7. Akpen G.D., Nwaogazie I.L., Leton T.G. // Journal of Applied Science and Technology. 2014. Vol. 19. No 1, 2. rr. 43-48.

8. Kudaybergenov K.K. Diss... d.f. (PhD). Almaty. 2012. $101 \mathrm{~s}$.

9. Poluchenie sorbentov karbonizatsiey risovoy shelukhi dlya ochistki vody ot nefteproduktov: [Elektronnyy resurs]. Rezhim dostupa:

Наинг Линн Сое - аспирант кафедры промышленной экологии, Российский химикотехнологический университет имени Д.И. Менделеева, Москва

Зин Мое - аспирант кафедры промышленной экологии, Российский химико-технологический университет имени Д.И. Менделеева, Москва

Мин Тху - аспирант кафедры промышленной экологии, Российский химико-технологический университет имени Д.И. Менделеева, Москва

Мьят Мин Тху - аспирант кафедры промышленной экологии, Российский химикотехнологический университет имени Д.И. Менделеева, Москва

Со Вин Мьинт - к.т.н., докторант кафедры промышленной экологии, Российский химикотехнологический университет имени Д.И. Менделеева, Москва

Нистратов Алексей Викторович - к.т.н., доцент кафедры промышленной экологии, Российский химико-технологический университет имени Д.И. Менделеева, Москва

Клушин Виталий Николаевич - д.т.н., професcop, профессор кафедры промышленной экологии, Российский химико-технологический университет имени Д.И. Менделеева, Москва
https://docviewet.yandex.ru/?urI=http $\% 3 \mathrm{~A} \% 2 \mathrm{~F}$ $\%$ 2Fpratsi.opu/ua\%2Fapp\% 2Fwebrootc. (data obrashcheniya: 3.08.2016).

10. Eletskiy P.M. Diss. na soiskanie uchenoy stepeni k.kh.n, Novosibirsk, 2009, 115 p.

11. KHolomeydik A.N. Diss. na soiskanie uchenoy stepeni k.kh.n. Vladivostok, 2016, 136 p.

12. Epifantseva N.S., Simkin YU.YA., Sovremennye problemy nauki $i$ obrazovaniya. RAEN, 2008, No 4, pp. 25-26.

13. Khalil L.B., Adsorpt. Sci. and Technol., 1996, Vol. 13, No 5, pp. 317-325.

14.Serbina T.V. Diss... k.t.n. M., MKHTI, 1993, 223 p.

15. Galushko L.YA., KHazipov V.A., Pashchenko L.V., Saranchuk V.I., KHimiya tverdogo topliva, 1998, No 3, pp. 33-37.

16.Kas'yanov G.I., Nematullaev I., Palagina I.A. i dr. Proizvodstvo aktivnogo uglya iz skorlupy kostochek plodovykh kul'tur i ego regeneratsiya: [Elektronnyy resurs]. https://cyberleninka.ru/article/n/proisvodstvoactivnogo-uglya-iz-... (data obrashcheniya: 17.06.2018).

17.Mukhin V.M., Klushin V.N. Proizvodstvo i primenenie uglerodnykh adsorbentov // Uchebnoe posobie. M.: RKHTU im. D.I. Mendeleeva. 2012. $308 \mathrm{~s}$.

18.Zubakhin N.P., Klushin V.N., Starostin K.G., Nistratov A.V. // Koks i khimiya. 2015. No 2. pp. 39-43.

Naing Lin Soe - post-graduate student of the Department of industrial ecology, Mendeleev Russian University of chemical technology, Moscow

Zin Moe - post-graduate student of the Department of industrial ecology, Mendeleev Russian University of chemical technology, Moscow

Min Thu - post-graduate student of the Department of industrial ecology, Mendeleev Russian University of chemical technology, Moscow

Myat Min Thu - post-graduate student of the Department of industrial ecology, Mendeleev Russian University of chemical technology, Moscow

Saw Win Myint - Ph. D., doctoral student of the Department of industrial ecology, D. I. Mendeleev Russian University of chemical technology, Moscow

Nistratov Alexey V. - Ph. D., associate Professor, Department of industrial ecology, Mendeleev Russian University of chemical technology, Moscow

Klushin Vitaly N. - doctor of technical Sciences, Professor, Professor of the Department of industrial ecology, Mendeleev Russian University of chemical technology, Moscow dvk1971april@mail.ru 